\title{
LIXIVIAÇÃO DE UM RESÍDUO DA PRODUÇÃO DE NÍQUEL PARA RECUPERAÇÃO DE ESCẨNDIO*
}

Ariane Gaspari Oliveira Souza ${ }^{1}$ Jorge Alberto Soares Tenório ${ }^{2}$

\section{Resumo}

O Escândio é um elemento do grupo das terras raras que apesar de ser tão abundante quanto metais como o chumbo, raramente é encontrado concentrado nos minérios. $A$ produção de Sc atual é inferior a 10t/ano proveniente do processamento de outros minérios e resíduos e também da recuperação de sucatas. Minérios lateríticos de níquel podem conter até 350ppm de Escândio e os resíduos do seu processamento podem ser ainda mais concentrados. Neste trabalho foi caracterizado um resíduo do processamento de minério de Níquel e avaliado o processo de lixiviação para reocupação do Escândio contido. Os principais componentes do resíduo são $\mathrm{Fe}, \mathrm{Cu}$, Ni e Co e o Escândio é da ordem de 1000ppm. A lixiviação do Escândio mostrou-se mais dependente da temperatura do que da concentração de $\mathrm{H}^{+}$e o processo de lixiviação proposto não foi seletivo para o Escândio sendo necessárias etapas subsequentes para purificação.

Palavras-chave: Escândio; Lixiviação; Terras raras; Resíduos.

\section{LEACHING OF A RESIDUE FROM NICKEL PRODUCTION FOR SCANDIUM RECOVERY}

\section{Abstract}

Scandium is a rare Earth element and besides being as abundant as Lead in the Earth's Crust, it is rarely found concentrated in minerals. Its production is less than $10 t /$ year, and it is obtained from other minerals and its residues processing, and from scrap recovery. Lateritic Nickel minerals can contain up to 350ppm of Scandium and the residues from its processing could be even more concentrated. In this paper a residue from Nickel production was characterized and the leaching process for Scandium recovery was studied. The main components of the residue are $\mathrm{Fe}, \mathrm{Cu}, \mathrm{Ni}$ e Co and Scandium content is around 1000ppm. Scandium leaching showed to be more dependent of the temperature than of concentration of $\mathrm{H}^{+}$and the leaching process proposed was not selective for Scandium, being necessary later purification steps.

Keywords: Scandium; Leaching; Rare earths; Residues

1 Engenheira Química, Mestranda em Engenharia Química, Escola Politécnica da Universidade de São Paulo, São Paulo, SP, Brasil

2 Professor Titular do Departamento de Engenharia Química, Escola Politécnica da Universidade de São Paulo, São Paulo, SP, Brasil 


\section{INTRODUÇÃO}

\subsection{O Escândio, sua ocorrência e aplicações}

O elemento escândio (Sc) pertencente ao grupo das terras raras é mais abundante na crosta terrestre que metais como chumbo, estanho, mercúrio e prata, sendo o $31^{\circ}$ elemento mais abundante com cerca de $22 \mathrm{ppm}^{1}$. Entretanto, raramente é encontrado concentrado devido a sua falta de afinidade pelos ânions formadores de minério mais comuns $^{2,3}$

A obtenção do Escândio, em consequência dessas concentrações, está associada à recuperação de sucatas ou como subproduto do processamento de outros minérios ${ }^{4}$. Usualmente o escândio contido nos minérios e resíduos é recuperado na forma de óxido $\left(\mathrm{Sc}_{2} \mathrm{O}_{3}\right)$ por processos hidrometalúrgicos, que incluem lixiviação, extração por solventes e precipitação ${ }^{4}$.

Fontes exploradas são apatitas, cassiterita, wolframita e minérios de urânio e de terras raras $^{1,4}$. Por substituir elementos como o ferro e o alumínio nas estruturas cristalinas de minerais o escândio é um elemento traço comum nas rochas constituídas por minerais ferromagnesianos com teores variando de 5 a 100 ppm 1 . O escândio pode ocorrer associado a minérios de alumínio, cobalto, ferro, molibdênio, níquel, fosfato, tântalo, titânio, tungstênio, zinco e zircônio ${ }^{1,5}$.

A demanda atual mundial de escândio é menor de 10 t/ano ${ }^{1}$, e é direcionada principalmente para a produção de ligas de alumínio para a indústria de equipamentos esportivos de alto desempenho e aeroespacial e a indústria de lâmpadas de descarga de alta intensidade ${ }^{1,4-6}$. O escândio ainda tem poucas aplicações industriais tanto pelo seu elevado preço - que varia de 900 a 5900 dólares por quilograma ${ }^{1}$ - quanto pela sua disponibilidade ${ }^{7-9}$.

\subsection{Recuperação de Escândio do processamento de Níquel}

Minérios lateríticos de Níquel em geral contém entre 50 e 110ppm de Escândio ${ }^{10} \mathrm{e} \mathrm{em}$ estudos geológicos mais recentes foram encontros minérios com até $350 \mathrm{ppm}^{11}$. Processos para recuperação do Níquel contido nesses minérios foram patenteados ${ }^{13-15}$.

Em 1998, Kimura e colaboradores ${ }^{12}$ desenvolveram um processo para recuperar os 25 a 60ppm de Sc contidos em um minério oxidado de Níquel. O processo envolve a lixiviação sob pressão do minério que é seletiva para o Sc em relação ao $\mathrm{Fe}$ e ao $\mathrm{Al}$ contidos. O Ni lixiviado é precipitado na forma de sulfeto e depois de removido o $\mathrm{Ni}$, o Sc é precipitado na forma de carbonato ou hidróxido que pode ser futuramente purificado por quelação, troca iônica ou extração por solventes.

Em 1999, Haslam e Arnall ${ }^{13}$ propuseram um método semelhante envolvendo lixiviação sob pressão e precipatação com sulfeto para remoção dos contaminantes seguida de precipitação do Sc na forma de hidróxido. Após a precipitação do Sc seguiram com a purificação por extração por solventes utilizando D2EHPA, Cyanex 272 e lonquest 801 . Os melhores resultados obtidos foram uma recuperação de $97,5 \%$ do Sc, utilizando Cyanex 272 em pH 1,0. Em seguida, 99,8\% do Sc extraído foi recuperado utilizando uma solução de ácido sulfúrico $\left(\mathrm{H}_{2} \mathrm{SO}_{4}\right) 400 \mathrm{~g} \cdot \mathrm{L}^{-1}$.

Em 2014, a Vale patenteou um processo para recuperação de Escândio de produtos intermediários do processamento hidrometalúrgico de minérios lateríticos ${ }^{14}$. A vantagem apresentada é o Escândio estar mais concentrado que nos minérios, cerca de 1100ppm, e o resíduo conter menores teores de $\mathrm{Ni}$ e Co em relação ao minério. O 
processo consiste em concentrar o Sc contido no resíduo a partir de lixiviação sulfúrica em $\mathrm{pH}$ entre 2,9 e 3,2, para lixiviar preferencialmente o Sc em relação aos outros metais contidos principalmente $\mathrm{Fe}, \mathrm{Al}$ e $\mathrm{Si}$, seguida de precipitação com carbonato de Sódio $\left(\mathrm{NaCO}_{3}\right)$ e óxido de magnésio $(\mathrm{MgO})$ em pH entre 5,0 e 5,5. Nessa etapa são eliminados parte do $\mathrm{Fe}$, Ni e Co contidos. Posteriormente, o precipitado enriquecido em Sc é lixiviado em meio básico com hidróxido de Sódio $(\mathrm{NaOH}) 2,5 \mathrm{~mol} . \mathrm{L}^{-1}$ a $50^{\circ} \mathrm{C}$ durante 30 minutos para remover o $\mathrm{Al}$ e a Si contidas resultando em um concentrado com Sc 0,8\%; Ni 13,6\%; Al 8,9\%; Fe 7,7\%; Si 6,9\%; S 0,08\%; Zn 0,31\% e Cu 1,7\%. O Sc contido nesse concentrado obtido poderia ser purificado por extração por solventes ou por troca iônica.

\subsection{Lixiviação}

O processo de lixiviação consiste em um processo de transferência de massa sólido-líquido, no qual ocorre uma dissolução seletiva dos metais presentes em um sólido através de uma solução aquosa contendo o agente lixiviante que pode ser um ácido, uma base ou um sal ${ }^{15}$.

No processo de lixiviação as etapas que determinam a cinética são o transporte de massa e a reação de dissolução. Dessa forma fatores como granulometria das partículas, agitação, temperatura, pressão e $\mathrm{pH}$ influenciam diretamente o processo ${ }^{16}$. As condições em que o processo de dissolução é termodinamicamente favorável são descritas na forma de um diagrama potencial Eh $\mathrm{x} \mathrm{pH}$ conhecido como diagrama de Pourbaix. Os diagramas são construídos para o equilíbrio a temperatura de $25^{\circ} \mathrm{C}$ e possuem portanto limitações, entretanto servem como um bom indicador para definição do processo ${ }^{15}$.

Em um sistema aquoso para potenciais abaixo da reação de evolução de hidrogênio (linha tracejada a da Figura 1) é esperado que na presença de uma solução ácida o Escândio seja encontrado dissolvido na forma de íons $\mathrm{Sc}^{3+}$ e $\mathrm{ScOH}^{+}$e que em meios alcalinos seja encontrado na forma de $\mathrm{Sc}(\mathrm{OH})_{3}$, conforme apresentado na Figura 1.

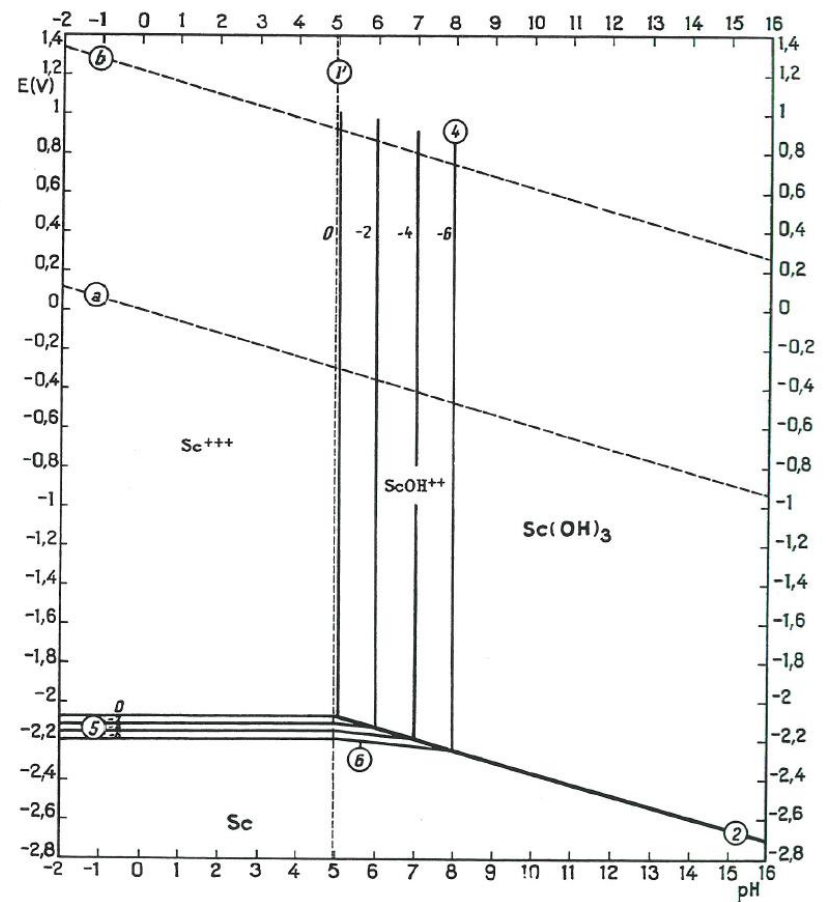

Figura 1. Diagrama de Pourbaix do Sc em água a $25^{\circ} \mathrm{C}^{17}$ 
A lixiviação sob pressão, conforme discutido anteriormente, tem sido aplicada em processos mais modernos para lixiviação seletiva do Escândio em relação a outros metais $^{12,13,18}$. Entretanto, o processo de lixiviação sob pressão apresenta custos de instalação maiores e maiores riscos do ponto de vista tecnológico em relação ao processo atmosférico ${ }^{19}$. Dessa forma, optou-se por avaliar o processo de lixiviação ácida a pressão atmosférica.

O ácido sulfúrico é comumente utilizado nos processos de lixiviação por ser abundante e relativamente barato e tem sido utilizado comercialmente nos processos de lixiviação de minerais na forma de óxidos, sulfetos e alguns silicatos e de fontes secundárias como sucatas e escórias ${ }^{20}$. Sendo assim, optou-se por sua utilização.

\section{MATERIAIS E MÉTODOS}

\subsection{Preparação e caracterização das amostras}

As amostras utilizadas nos ensaios foram preparadas a partir de um resíduo gerado na cadeia de processamento de minério de níquel. Esse resíduo, aqui denominado resíduo, é um precipitado coletado do fundo de um espessador, no qual ocorre a remoção de metais indesejados do circuito principal, na forma de um hidróxido. Além dos hidróxidos metálicos, o resíduo contém também outros elementos como perlita, carvão e material orgânico adsorvido provenientes do descarte do sistema de filtração da unidade industrial onde é processado. Para caracterização química do resíduo e quantificação dos principais componentes foram utilizados dois métodos de abertura da amostra: digestão com quatro ácidos e fusão com metaborato de Lítio. A quantidade de material orgânico no resíduo foi determinada através de ensaio de perda ao fogo.

A digestão utilizando quatro ácidos: clorídrico $(\mathrm{HCl})$, nítrico $\left(\mathrm{HNO}_{3}\right)$, fluorídrico $(\mathrm{HF})$ e perclórico $\left(\mathrm{HClO}_{4}\right)$, também conhecida como digestão "quase-total" é uma técnica comumente utilizada em mineralogia e permite a dissolução da maioria dos compostos sulfetados e silicatados, entretanto esse método dissolve apenas a porção lixiviável das terras raras $^{21}$. Dessa forma, a análise foi complementada com a fusão com metaborato de Lítio, que permite abertura completa da amostra, incluindo espécies minerais refratárias ${ }^{21}$.

As amostras abertas pelos dois métodos foram analisadas por Espectrometria de Emissão Atômica por Plasma Acoplado Indutivamente (ICP-AES).

Para caracterização física do resíduo foram utilizadas as técnicas de Difração de raios X (DRX) e Microscopia Eletrônica de Varredura (MEV).

\subsection{Lixiviação}

A lixiviação do resíduo foi realizada em reatores de 5 bocas de fundo chato fechados de $1000 \mathrm{~mL}$ sob agitação magnética. Para cada concentração de solução de ácido sulfúrico ensaiada, foram utilizadas três temperaturas distintas, conforme apresentado na Tabela 1. 
Tabela 1. Concentração de $\mathrm{H}^{+}$e temperatura utilizadas nos ensaios de lixiviação

\begin{tabular}{ccc}
\hline Ensaio & {$\left[\mathbf{H}^{+}\right]\left(\mathbf{m o l}^{-\mathbf{L}^{-1}}\right)$} & $\begin{array}{c}\text { Temperatura } \\
\left({ }^{\circ} \mathbf{C}\right)\end{array}$ \\
\hline Lix A & 0,5 & 25 \\
Lix B & 0,5 & 40 \\
Lix C & 0,5 & 70 \\
Lix D & 1,0 & 25 \\
Lix E & 1,0 & 40 \\
Lix F & 1,0 & 70 \\
Lix G & 2,0 & 25 \\
Lix H & 2,0 & 40 \\
Lix I & 2,0 & 70 \\
\hline
\end{tabular}

O material foi lixiviado em $350 \mathrm{~mL}$ de uma solução de ácido sulfúrico diluído pré-aquecida a temperatura desejada, conforme Tabela 1. mantendo a relação sólidos 1:10. A solução ácida na concentração pré-determinada foi aquecida por chapa elétrica e a temperatura controlada por termômetro com uma variação máxima de $\pm 2^{\circ} \mathrm{C}$, após o atingimento da temperatura desejada foi adicionada uma fração do resíduo. A velocidade de agitação foi mantida constante em $750 \mathrm{rpm}$ de modo a manter a solução homogênea. A Figura 2 ilustra a montagem do experimento.

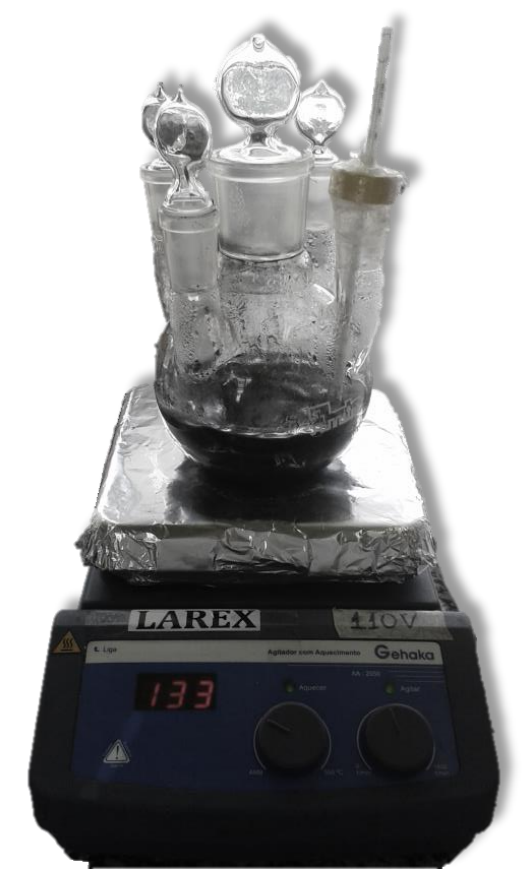

Figura 2. Ilustração do esquema utilizado no ensaio de lixiviação

Ensaios preliminares indicam que não há variação no percentual de lixiviação dos metais após 4 horas. Ao final do período de lixiviação de 4 horas, a solução do reator foi filtrada a vácuo e o filtrado foi armazenado como contraprova. A torta da filtração foi seca em estufa e pesada para análise e balanço de massa.

As alíquotas do filtrado coletadas foram diluídas em uma solução de $\mathrm{HNO}_{3} 3 \%$ e analisadas por ICP-OES e os resíduos de lixiviação foram analisados IPC-AES, após abertura com quatro ácidos para quantificação dos metais. 


\section{RESULTADOS E DISCUSSÃO}

\subsection{Caracterização das amostras}

Os resultados dos principais componentes do resíduo estão apresentados na Tabela 2.

Tabela 2. Principais componentes do resíduo por ICP-AES

\begin{tabular}{ccccccccccc}
\hline & Al & Co & Cu & Fe & Na & Ni & P & S & Sc & $\mathbf{S i O}_{2}$ \\
\hline $\begin{array}{c}\% \text { em } \\
\text { massa }\end{array}$ & 0,98 & 0,98 & 7,83 & 5,56 & 2,25 & 2,69 & 4,11 & 5,96 & 0,097 & 13,73 \\
\hline
\end{tabular}

O teor de Escândio de 970ppm contido no resíduo pode tornar o processo de recuperação economicamente viável em relação a recuperação direta do minério, pois em geral minérios lateríticos explorados para recuperação de Ni e Co contem teores de Escândio da ordem de dezenas a centenas de partes por milhão e sua concentração na solução de processo fica abaixo de $20 \mathrm{mg} \cdot \mathrm{L}^{-1}$ tornando sua recuperação custosa por tratar grandes volumes ${ }^{14}$.

A perda ao fogo foi de $45,8 \%$ em massa, esse valor elevado está relacionado ao carbono e material orgânico adsorvido contidos no resíduo.

Em relação a caracterização física do resíduo, no difratograma obtido por DRX não foram obtidos picos bem definidos, caracterizando um material amorfo. Nas imagens obtidas por MEV não foi possível detectar formações ricas em Escândio, estando o elemento portanto, disperso na amostra.

\subsection{Lixiviação}

Os resultados da lixiviação estão apresentados na Tabela 3. Conforme esperado, o percentual de extração dos metais aumenta tanto com o aumento da concentração de $\mathrm{H}^{+}$da solução, quanto com o aumento da temperatura. Esse efeito é mais acentuado para o Cobre, que na condição mais branda a lixiviação é de $59,3 \%$ e na condição mais severa é de $85,5 \%$.

Tabela 3. Resultados da Lixiviação do resíduo em $\mathrm{H}_{2} \mathrm{SO}_{4}$ variando temperatura e concentração de $\mathrm{H}^{+}$

\begin{tabular}{|c|c|c|c|c|c|c|}
\hline \multirow{2}{*}[\mathrm{H}^{+}]{$\left(\mathrm{mol}^{-\mathrm{L}^{-1}}\right)$} & \multirow{2}{*}{$\mathrm{T}\left({ }^{\circ} \mathrm{C}\right)$} & \multicolumn{5}{|c|}{ Lixiviação (\%) } \\
\hline & & $\mathrm{Fe}$ & $\mathrm{Cu}$ & $\mathrm{Ni}$ & Co & Sc \\
\hline \multirow{3}{*}{0,5} & 25 & 81,2 & 59,3 & 81,5 & 87,5 & 89,5 \\
\hline & 40 & 81,4 & 63,8 & 81,6 & 87,0 & 89,8 \\
\hline & 70 & 82,6 & 76,5 & 88,1 & 89,1 & 91,2 \\
\hline \multirow{3}{*}{1,0} & 25 & 82,2 & 60,5 & 81,6 & 87,5 & 90,5 \\
\hline & 40 & 82,4 & 65,5 & 82,3 & 87,5 & 91,0 \\
\hline & 70 & 87,1 & 84,6 & 90,4 & 89,6 & 92,3 \\
\hline \multirow{3}{*}{2,0} & 25 & 83,3 & 62,7 & 82,4 & 87,4 & 90,8 \\
\hline & 40 & 84,2 & 69,8 & 84,6 & 87,8 & 91,6 \\
\hline & 70 & 89,8 & 85,5 & 90,6 & 88,9 & 92,5 \\
\hline
\end{tabular}


Os resultados indicam que a extração do Escândio do resíduo é mais dependente da temperatura do que da concentração de $\mathrm{H}^{+}$, pois o aumento da extração é mais acentuado com o aumento da temperatura (Figura 3). O maior percentual de lixiviação do Escândio foi observado na concentração de $2,0 \mathrm{~mol} \cdot \mathrm{L}^{-1}$ na temperatura de $70^{\circ} \mathrm{C}$.
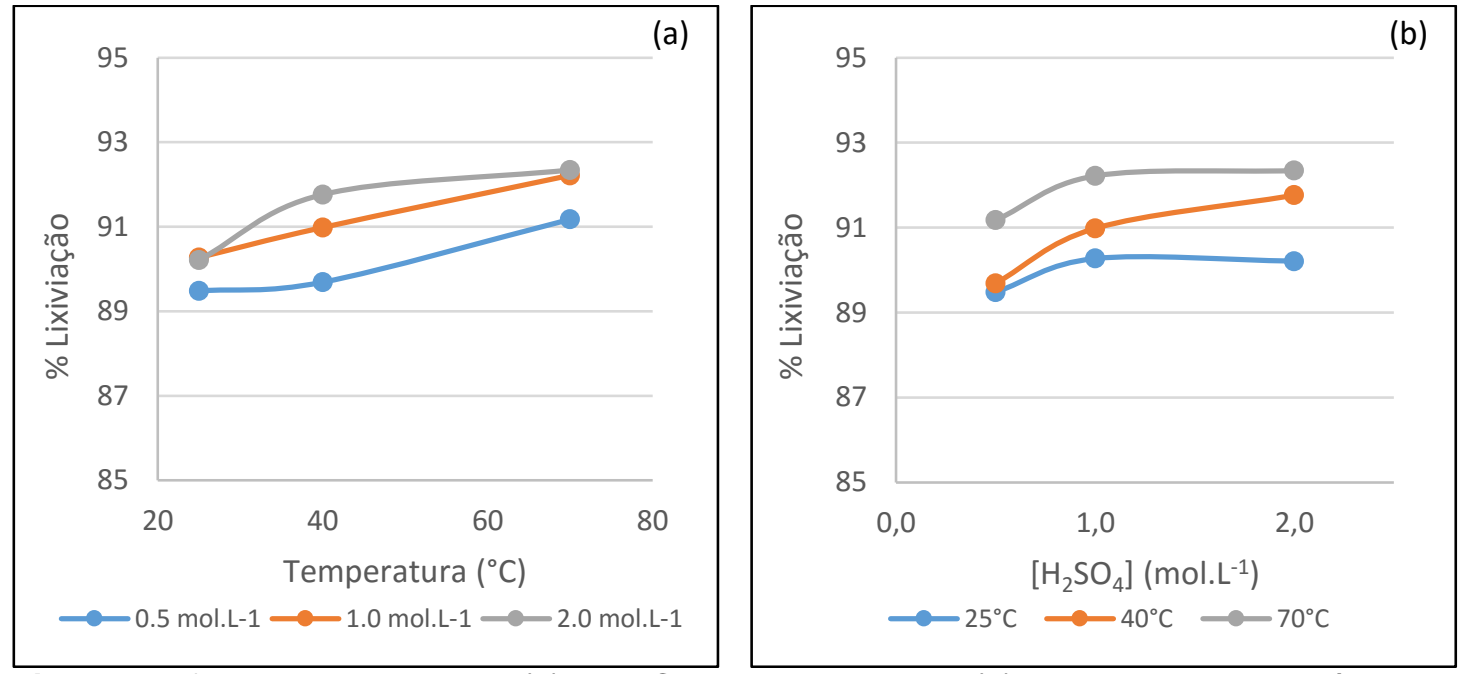

Figura 3. Efeito da Temperatura (a) e da Concentração de $\mathrm{H}^{+}$(b) na lixiviação do Escândio do resíduo

Os resultados de extração obtidos a temperatura de $70^{\circ} \mathrm{C}$ na solução de ácido sulfúrico $0,5 \mathrm{~mol} . \mathrm{L}^{-1}$, que nas condições de ensaio equivalem a um consumo de ácido de $490 \mathrm{~kg} \cdot \mathrm{t}^{-1}$ de resíduo, são melhores que os obtidos por Pery et al ${ }^{18}$ no processo de lixiviação sob pressão a $255^{\circ} \mathrm{C}$ de minério laterítico com um consumo de ácido de 355 a $448 \mathrm{~kg} . \mathrm{t}^{-1}, 91,2 \%$ comparado a $88,7 \%$. Entretanto, o percentual de $\mathrm{Fe}$ extraído também é consideravelmente maior, 82,6\% em comparação a 1,0 a 2,2\%.

Os resultados obtidos e os apresentados por Pery et al ${ }^{18}$ comprovam não há diferenças significativas para a lixiviação do Escândio nos processos atmosféricos e sob pressão. A lixiviação sob pressão favorece apenas a redução do percentual de extração do Ferro.

Já em comparação aos resultados apresentados no processo de lixiviação a pressão atmosférica de um produto intermediário do processamento do minério laterítico ${ }^{14}$, os resultados obtidos são inferiores. Enquanto o produto intermediário apresentou recuperação de $99,9 \%$ do Sc contido quando lixiviado em $\mathrm{pH} 0,5^{14}$ (equivalente a uma solução com concentração de ácido sulfúrico de $0,32 \mathrm{~mol}^{-L^{-1}}$ ), o resíduo lixiviado a 0,5mol. $\mathrm{L}^{-1}$ e temperatura ambiente apresentou $89,5 \%$ de recuperação do Sc. A diferença observada entre os percentuais de lixiviação do Escândio nos processos está associada a própria composição do resíduo.

\section{CONCLUSÃO}

A extração do Escândio do resíduo é mais dependente da temperatura do que da concentração de $\mathrm{H}^{+}$. Nas condições avaliadas, o maior percentual de lixiviação do Escândio (92,5\%), é observado na concentração de $2,0 \mathrm{~mol}^{-\mathrm{L}^{-1}}$ na temperatura de $70^{\circ} \mathrm{C}$.

Essas condições não são seletivas e os demais metais presentes também são lixiviados, sendo necessárias etapas subsequentes de purificação como precipitação e extração por solventes. 


\section{REFERÊNCIAS}

1 GAMBOGI, J. Mineral Commodity Summaries, Scandium. U.S. Geologycal Survey, v. 1, n. 703, p. 140-141, 2013.

2 GAMBOGI, B. J.; CORDIER, D. J.; GEORGE, B. M. W. 2010 Minerals Yearbook. Environmental Protection, , n. September, p. 7, 2011.

3 GAMBOGI, J. 2012 Minerals Yearbook Rare Earths [Advanced Release]. U.S. Geologycal Survey, 2015.

4 GUPTA, C. K.; KRISHNAMURTHY, N. Extractive Metallurgy of Rare Earths. Boca Raton: CRC Press, 2005. $537 \mathrm{p}$.

5 NAUMOV, A V. Review of the World Market of Rare-Earth Metals. Metallurgy of rare and noble metals, v. 49, n. 1, p. 14-22, 2008.

6 ENGHAG, P. Encyclopedia of the Elements: Technical Data - History - Processing Applications. John Wiley \& Sons, 2008. 1309 p.

7 WANG, W.; PRANOLO, Y.; CHENG, C. Y. Metallurgical processes for scandium recovery from various resources: A review. Hydrometallurgy, v. 108, n. 1-2, p. 100-108, 2011. Elsevier B.V.

8 RØYSET, J. Scandium in Aluminium alloys overview: Physical Metallurgy, Properties and applications. Metallurgical Science and Technology, v. 25, p. 11-21, 2007.

9 SAKAI, N.; YAMAJI, K.; HORITA, T.; XIONG, Y.; YOKOKAWA, H. Rare-earth materials for Solid Oxide Fuel Cells (SOFC). Handbook on the Physics and Chemistry of Rare Earths, v. 35, n. 05, p. 1-43, 2005.

10 FRONDEL, C. Section 21 - Scandium. In: K. H. Wedepohl (Org.); Handbook of Geochemistry. p.21-A1 a 21-O1, 1970. Heidelberg: Springer-Verlag Berlin.

11 SCANDIUM INTERNATIONAL MINING Corp. EMC Metals enters Agreement to Explore and Develop Australian Rare Earth Scandium Deposit. Disponível em: $<$ http://www.emcmetals.com/s/NewsReleases.asp?ReportID=499020\&_Type=NewsReleases\&_Title=EMC-Metals-enters-Agreement-to-Explore-and-Develop-AustralianRare-Earth-Sc...> Acesso em: 3 set.2013.

12 PACIFIC METALS Co.(Japan). KIMURA, A.; MURAI, K.; YAKUSHIJI, H. Process for recovering rare earth metal from oxide ore by concentration and separation. US5756056, 1998.

13 HASLAM, M.; ARNALL, B. An Investigation into the Feasibility of Extracting Scandium from Nickel Laterite Ores. ALTA 1999 - NICKEL/COBALT PRESSURE LEACHING \& HYDROMETALLURGY FORUM. Anais... . p.18, 1999. Perth.

14 Vale S.A. (Brasil). MIHAYLOV, I.; PETERSON, R.; SINGHAL, A.; MASSEY, C. Method for Recovering Scandium from Intermediate Products Formed in the Hydrometallurgical Processing of Laterite Ores. US2014/0314639 A1, 2014.

15 GUPTA, C. K. Chemical Metallurgy Principles and Practice. Weinheim: Wiley-VCH, 2003. $811 \mathrm{p}$.

16 MOORE, J. J. Chemical Metallurgy. Elsevier, 2013. 456 p.

17 POURBAIX, M. Atlas of electrochemical equilibria in aqueous solutions. Oxford: Pergamon Press, 1974. 644 p.

18 PERY, K.; BECKER, G.; GILLIES, A.; MASON, P. Scandium Breaths New Life Into Old Greenvale Nickel Mine. ALTA 2012 - NICKEL/COBALT PRESSURE LEACHING \& HYDROMETALLURGY FORUM. Anais... . p.10, 2012. Perth.

19 MCDONALD, R. G.; WHITTINGTON, B. I. Atmospheric acid leaching of nickel laterites review. Part I Sulfuric acid technologies. Hydrometallurgy, v. 91, p. 35-55, 2008.

20 GUPTA, C. K.; MUKHERJEE, T. K. Hydrometallurgy in Extraction Processes, Volume I. CRC Press, 1990. 248 p.

21 ALS. ALS Geochemistry - Schedule of Services \& Fees. Disponível em: <http://www.alsglobal.com/en/Our-Services/Minerals/Geochemistry/Service-Schedule> Acesso em: 3 out.2015. 